\title{
Arsenate Removal from Water by Simultaneous Green Tea Nano-Zerovalent Iron and Ultrasonic Wave
}

\author{
Abolfazl Ashouri, ${ }^{1}$ Bagher Anvaripour, ${ }^{1}$ \\ Mohsen Motavassel, ${ }^{1}$ and Nematolah Jaafarzadeh Haghighifard ${ }^{2,3}$ \\ ${ }^{1}$ Abadan Faculty of Petroleum Engineering, Petroleum University of Technology, Abadan 63187 14331, Iran \\ ${ }^{2}$ Environmental Technology Research Center, Jundishapur University of Medical Sciences, Ahwaz 61357 15751, Iran \\ ${ }^{3}$ School of Public Health, Ahwaz Jndishapur University of Medical Sciences, Ahwaz 61357 15751, Iran
}

Correspondence should be addressed to Bagher Anvaripour; anvaripour@put.ac.ir

Received 21 February 2014; Accepted 23 March 2014; Published 9 April 2014

Academic Editors: K. Z. Elwakeel and S. Wang

Copyright (C) 2014 Abolfazl Ashouri et al. This is an open access article distributed under the Creative Commons Attribution License, which permits unrestricted use, distribution, and reproduction in any medium, provided the original work is properly cited.

\begin{abstract}
Nano-zerovalent iron (NZVI) was synthesized using green tea (GT) extract and it was used as an adsorbent in arsenate removal from water. FESEM, PSD, and XRD employed in the examination of particles and their characterizations. Results showed that the particles were spherical lumped together in a texture structure with sizes ranging from 20 to 70 nanometers. All experiments were accomplished in a batch mode. Adsorption isotherm, adsorption kinetics, and the effects of $\mathrm{pH}$, GT-NZVI dosage, and ultrasonic wave power on arsenate separation capabilities were explored. The results suggested that the arsenate removal efficiency enhanced with increasing GT-NZVI dosage. Increase in $\mathrm{pH}$ from 3 to approximately 6 leads to increase in the removal efficiency; however, increasing the $\mathrm{pH}$ further decreased the removal efficiency. The effect of ultrasonic power on $\mathrm{As}(\mathrm{V})$ removal was dependent on $\mathrm{pH}$ and NZVI dosages. The positive effect was more pronounced at low adsorbent dosages and acidic solution in which the As(V) removal efficiency improved with increasing ultrasonic power. However, in highly alkali solutions As(V) removal efficiency reduced with increasing ultrasonic power. The adsorption kinetics followed second order, while the adsorption isotherm was fitted best with Langmuir equation at a maximum capacity of $34.2 \mathrm{mg} \mathrm{g}^{-1}$.
\end{abstract}

\section{Introduction}

The expression of heavy metals in environmental field refers to a category of metals and metalloids that have a rather high density and are poisonous or toxic even at small concentrations. They consist of arsenic, mercury, cadmium, chromium, lead, barium, and so forth [1]. Arsenic found in surface and ground water turned out to be a main danger for the human being and helpful microorganisms [2-7]. Arsenic amount in water can increase because of some emission sources such as mineral dissolution, pesticide usage, fly ash release and disposal, mine drainage, and geothermal discharge [8].

Inorganic species of arsenate ions such as $\mathrm{H}_{3} \mathrm{AsO}_{4}$, $\mathrm{H}_{2} \mathrm{AsO}_{4}{ }^{-} \mathrm{HAsO}_{4}{ }^{2-}, \mathrm{AsO}_{4}{ }^{3-}$, and arsenite ions, for example, $\mathrm{H}_{3} \mathrm{AsO}_{3}, \mathrm{H}_{2} \mathrm{AsO}_{3}{ }^{-}$, and $\mathrm{HAsO}_{3}{ }^{2-}$ are the main types of arsenic found in groundwater and surface water [9]. As(V) exists as $\mathrm{H}_{2} \mathrm{AsO}_{4}{ }^{-}$and $\mathrm{HAsO}_{4}{ }^{2-}$ near $\mathrm{pH}$ 7, while the $\mathrm{As}(\mathrm{III})$ type is found as $\mathrm{H}_{3} \mathrm{AsO}_{3}{ }^{0}$ at $\mathrm{pH}$ less than 9.2. Furthermore, As(III) species exist in soil and groundwater at anaerobic conditions (small redox potential) but $\mathrm{As}(\mathrm{V})$ is favored at a redox potential more than $100 \mathrm{mV}$ and in oxygenated water [9]. The amount of arsenic species found in water is primarily dependent on redox potentials [10].

Arsenic is considered as a carcinogen for human being by the International Agency for Research on Cancer and the National Research Council [11]. To protect people from poisonous arsenic, the World Health Organization (WHO) and several worldwide legislator organizations recommended a maximum permissible concentration of $10 \mu \mathrm{g} / \mathrm{L}$ in water [12]. As the present amount of arsenic in drinking water at small concentrations brings about critical health outcomes, separation of arsenic has emerged increasingly vital [12].

There are numerous processes for arsenic removal including coagulation, precipitation, reverse osmosis, membrane 
separation, microfiltration, ion-exchange, ozone oxidation, bioremediation, and adsorption techniques [11, 13]. Most of the used arsenic separation processes have great maintenance cost and need comparatively costly sorbents adsorbents. Consequently, arsenic adsorption by metals from water has gained extra consideration because of its excessive application performance and low cost [11].

Removal of As(III) and As(V) from groundwater by zerovalent iron has become one of the most widespread practice in recent years [14]. The reaction velocity of zerovalent iron has been enhanced greatly by the introduction of nano-zerovalent iron [9]. Many authors have reported the capability of NZVI in the removal of arsenic ions from water $[9,10,15]$.

Many chemical and physical procedures are used to synthesize NZVI of certain sizes and characteristics [16]. The aggregation of NZVI particles to form chain-similar arrangement is responsible for decreasing interfacial area [15]. Aggregation prevention of NZVI particles to stabilize them can be performed by conveying electrostatic repulsion, using organic surfactants, utilizing coating, or synthesizing them by means of support of inorganic material [16].

In synthesizing NZVI, sodium borohydride is widely used; however, it is very toxic [17]. Saving the environment requires that sodium borohydride is replaced with a more friendly substance. Green tea is recognized to include polyphenols acting as both reducing and coating agents for Fe [17]. In addition to it being biodegradable, green tea has a high water solubility and low toxicity [17]. These favorable properties of green tea make it a good candidate for replacing sodium borohydride in synthesizing NZVI.

There are limited data on capability of GT-NZVI to uptake arsenate from polluted water. Furthermore, the effect of ultrasonic power on this removal requires more research. An effort has been made in this paper to fill the mentioned gap and provide more data. In this study, NZVI particles were synthesized using extract of green tea leaves at ambient temperature and pressure. The major objective of the present work is to examine the capability of synthesized GT-NZVI in the elimination of As(V) from water. Another goal of this study is to find the adsorption isotherm of As(V). Furthermore, the effects of GT-NZVI dosage, $\mathrm{pH}$, and ultrasonic wave power on $\mathrm{As}(\mathrm{V})$ uptake from water are examined.

\section{Materials and Methods}

2.1. Materials Used. $\mathrm{Na}_{2} \mathrm{HAsO}_{4} \cdot 7 \mathrm{H}_{2} \mathrm{O}, \mathrm{FeSO}_{4} \cdot 7 \mathrm{H}_{2} \mathrm{O}, \mathrm{HCl}$, and $\mathrm{NaOH}$ were reagent grade obtained from Sigma Aldrich Chemical Co. Green tea obtained from Refaah brand, Iran.

2.2. Equipment Used. Agitator (CAT 100CL), pH meter (jenway-3510), power ultrasonic bath (AS ONE), UP 200 H, UIP 1000 hd from Hielschler Company, vacuum filter (ROCKER 610), PerkinElmer atomic absorption spectrophotometer (USA) equipped with a graphite furnace HGA, field emission scanning electron microscope (HITACHI-4160), XRD (Philips X'Pert Pro D/MAX-RB, RIGAKU, Tokyo,
Japan), and Qudix particle size analyzer (Republic of Korea) were used in this study.

2.3. Experimental Preparation. All glass vessels and tubes used in test scrubbed and acid cleaned using $10 \%$ aqueous nitric acid and then triple-rinsed with deionized water. Arsenate aqueous solution of concentration $5 \mathrm{mg} / \mathrm{L}$ was prepared on the day of experimentation by diluting the stock solution with deionized water. Hydrochloric acid (1 M) and sodium hydroxide $(1 \mathrm{M})$ used for adjusting the $\mathrm{pH}$ using a calibrated $\mathrm{pH}$ meter. All experiments were conducted at laboratory temperature $\left(25 \pm 1^{\circ} \mathrm{C}\right)$.

2.4. Synthesis of GT-NZVI. The preparation of NZVI was performed using green tea extracts [16]. Green tea extract was made by heating green tea until boiling; one liter of deionized water was boiled in a beaker and then a quantity of $20 \mathrm{~g}$ green tea was added to it. The beaker was covered with an aluminum foil and the tea was heated for further 5 minutes. After that, the beaker was removed from the heater and the tea leaves left to settle for one hour and cooled to reach the room temperature $\left(25^{\circ} \mathrm{C}\right)$. Finally, the green tea extract was vacuum-filtered. Independently, in a one-liter balloon, a solution of $0.10 \mathrm{M} \mathrm{FeSO} \cdot 7 \mathrm{H}_{2} \mathrm{O}$ was made by dissolving $28.7 \mathrm{~g}$ of solid $\mathrm{FeSO}_{4} \cdot 7 \mathrm{H}_{2} \mathrm{O}$ in sufficient deionized water (to get one liter solution). Afterward, the solution of $0.10 \mathrm{M}$ $\mathrm{FeSO}_{4} \cdot 7 \mathrm{H}_{2} \mathrm{O}$ was added in a dropwise manner to the green tea extract in $2: 3$ volume ratio in the beaker under magnetic stirring $(600 \mathrm{rpm})$ at room temperature for 5 minutes. Next, 1.0 $\mathrm{M} \mathrm{NaOH}$ or $\mathrm{HCl}$ aqueous solution was added dropwise until the $\mathrm{pH}$ was 6.0. Evidence of intense black precipitate manifested as the appearance of GT-NZVI particles. The GTNZVI particles were then separated first by evaporating most of water from the solution using a hot plate and afterward by drying them overnight in a fume hood $[1,17-19]$.

2.5. Adsorption Isotherm. The adsorption experiments conducted using a batch system. One hundred $\mathrm{mL}$ of $\mathrm{As}(\mathrm{V})$ solution with an initial concentration of $5 \mathrm{mg} \mathrm{L}^{-1}$ was poured in a $250 \mathrm{~mL}$ Erlenmeyer flask. Then a specific amount of GT-NZVI was added to the flask. The $\mathrm{pH}$ of the resulting solution was adjusted to 6 by adding $1 \mathrm{M} \mathrm{HCl}$ or $\mathrm{NaOH}$ using a calibrated $\mathrm{pH}$ meter. The content of Erlenmeyer flask was mixed next by means of magnetic stirrer at speed of $350 \mathrm{rpm}$ at laboratory temperature $\left(25 \pm 1^{\circ} \mathrm{C}\right)$. After reaction completion, the flask removed from magnetic stirrer and allowed to settle for $5 \mathrm{~min}$ at laboratory temperature. Subsequently the adsorbent separated by centrifuging the solution at speed of $3000 \mathrm{rpm}$ for $15 \mathrm{~min}$. Finally, $50 \mathrm{~mL}$ of treated sample filtered through a $0.45 \mu$ Millipore membrane. A PerkinElmer (USA) atomic absorption spectrophotometer equipped with a graphite furnace HGA, a cathode-ray (EDL lamp), a palladium matrix modifier, and WinLab32 software was used to measure of $\mathrm{As}(\mathrm{V})$ in treated samples [20]. The detection limit of the instrument was $0.3 \mu \mathrm{g} / \mathrm{L}$.

2.6. Ultrasonic Effect on Adsorption. The adsorption runs were performed in a batch system as stated in the previous 


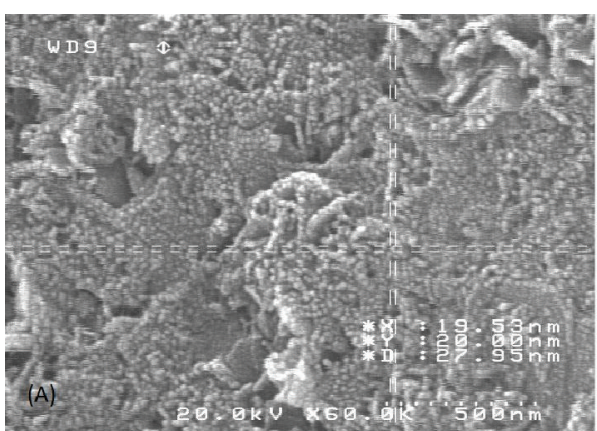

(a)

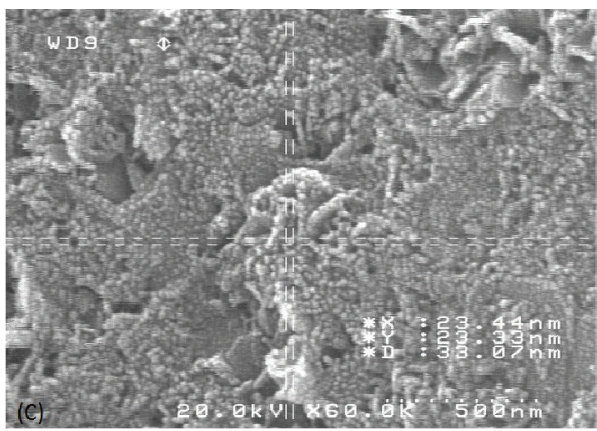

(c)

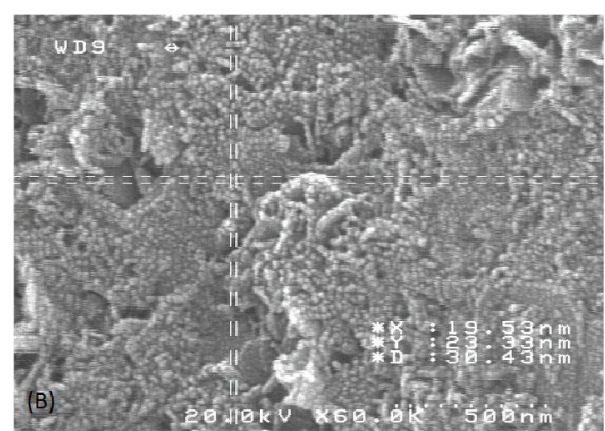

(b)

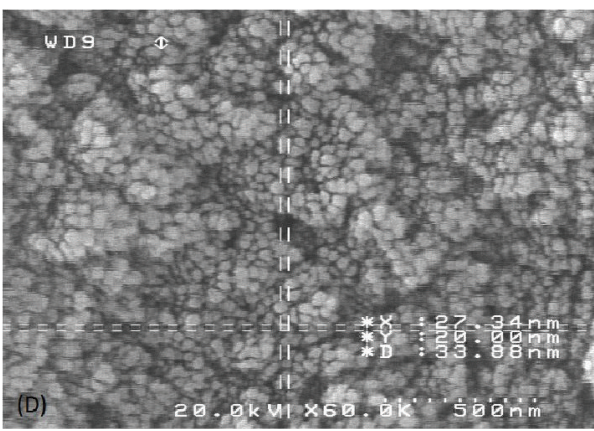

(d)

FiguRE 1: FESEM analysis of GT-NZVI structure. (a) Diameter $=27.95 \mathrm{~nm}$, (b) diameter $=30.43 \mathrm{~nm}$, (c) diameter $=33.07 \mathrm{~nm}$, and (d) diameter $=33.88 \mathrm{~nm}$.

section except for mixing method; ultrasonic device was used instead of the magnetic stirrer. Two sets of experiments were conducted with ultrasonic powers of 150 and $300 \mathrm{~W}$, while the dosage of adsorbent was set at $0.1,0.55$, and $1 \mathrm{gL}^{-1}$ and $\mathrm{pH}$ was adjusted at 3,7 , and 11 . In each experiment, the solution mixed for 15 minutes using ultrasonic power. At the end of each experiment, $50 \mathrm{~mL}$ of treated sample was filtered through a $0.45 \mu$ Millipore membrane. GF-AAS technique was employed for measuring the concentration of $\mathrm{As}(\mathrm{V})$ in treated samples.

2.7. Adsorption Kinetics. Seven experiments were carried out to determine the kinetics rate constants of arsenate adsorption by GT-NZVI at seven time intervals (including $5,30,60,90,120,180$, and $210 \mathrm{~min}$ ). In each run, $0.1 \mathrm{~g}$ of GT-NZVI was added to a beaker containing $100 \mathrm{~mL}$ of solution of $5 \mathrm{ppm}$ arsenate at $\mathrm{pH}$ 6. The content of beaker was mixed using a magnetic stirrer at laboratory temperature $\left(25 \pm 1^{\circ} \mathrm{C}\right)$ for the required time. At the end of each run, the remaining $\mathrm{As}(\mathrm{V})$ in the filtered sample was measured by HGAAS method. Each experiment was done in duplicate and the mean value was reported.

\section{Results and Discussion}

3.1. Characterization of GT-NZVI Particles. The synthesized GT-NZVI particles were characterized via FESEM, XRD, and PSD techniques. The GT-NZVI particles were distributed over adhesive carbon tapes held on metallic disks, and their

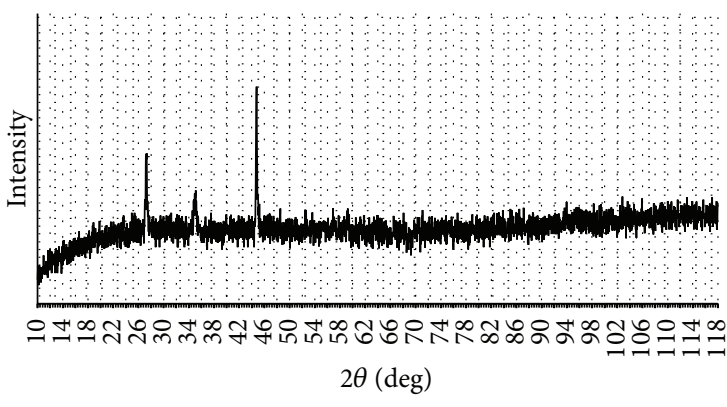

FIGURE 2: XRD pattern of GT-NZVI.

images were taken at several magnifications using FESEM. The FESEM image illustrated in Figure 1 shows the GT-NZVI particle sizes and structures. As indicated in Figure 1(d), GTNZVI particles consisted of spherical particles assembled in texture structure. Figures 1(a), 1(b), and 1(c) also indicate that the GT-NZVI particles have diameters around $30 \mathrm{~nm}$.

The structure of GT-NZVI particles was found using XRD type apparatus and the results are demonstrated in Figure 2. The samples of GT-NZVI were washed three or four times with pure ethanol before XRD analysis to decrease the $\mathrm{NaCl}$ amount that crystallized out during the production stage and scanned within the $2 \theta$ limit of $0-118^{\circ}$. The scanning rate set at $2.0^{\circ} / \mathrm{min}$ considered all most important varieties of iron and iron oxides. The XRD pattern of unused GT-NZVI particles indicates a major characteristic peak at $2 \theta$ degrees of 44.71 showing the existence of zerovalent iron $\left(\mathrm{Fe}^{0}\right)$. In addition, 


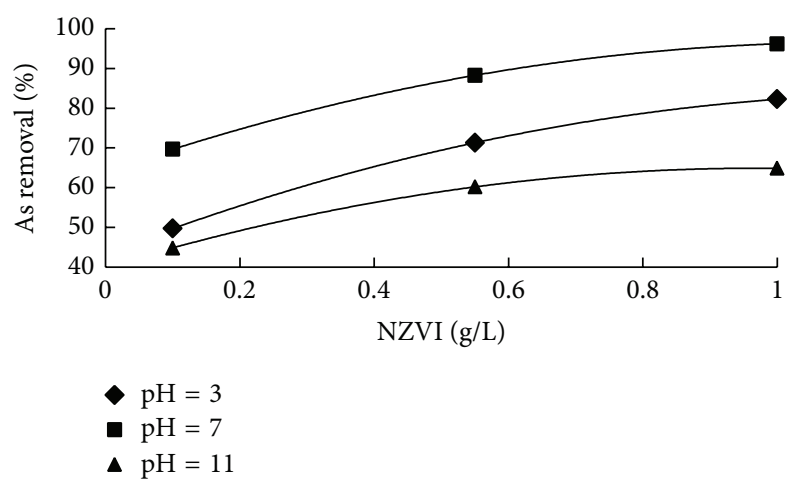

(a) Ultrasonic power $=0 \mathrm{~W}$

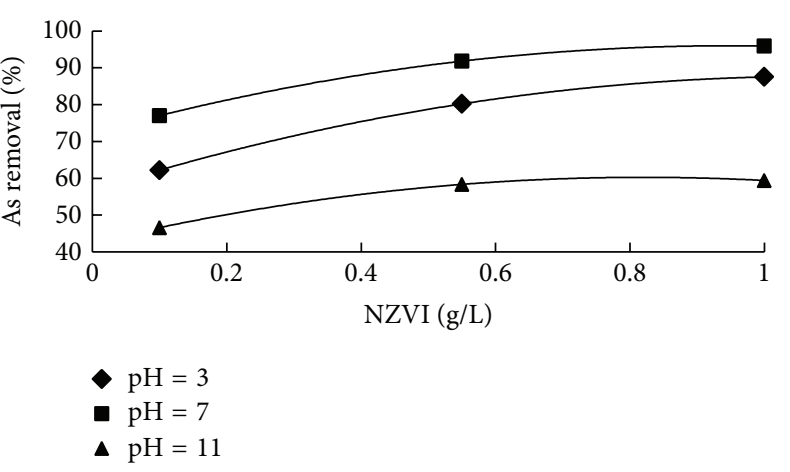

(b) Ultrasonic power $=150 \mathrm{~W}$

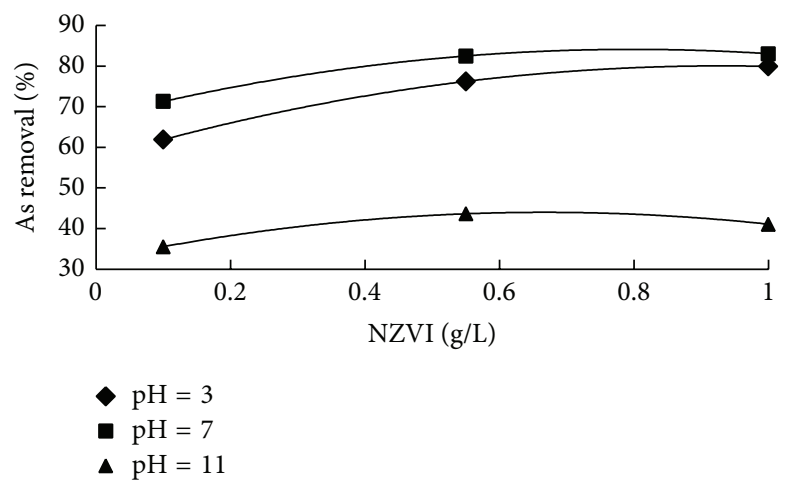

(c) Ultrasonic power $=300 \mathrm{~W}$

FIGURE 3: As(V) removal efficiency versus GT-NZVI concentration.

the figure demonstrates two other peaks that are relatively smaller at $2 \theta$ degrees of 27.2 and 35 that are related to the presence of iron hydroxide $(\mathrm{FeOOH})$ and $\mathrm{Fe}_{3} \mathrm{O}_{4}$, respectively.

3.2. Effect of GT-NZVI Dosage. Adsorption of arsenate by GT-NZVI was investigated using $5 \mathrm{mg} / \mathrm{L} \mathrm{As}(\mathrm{V})$ solution at three different GT-NZVI concentrations of $0.1,0.55$, and $1 \mathrm{~g} / \mathrm{L}$ at constant ultrasonic power and $\mathrm{pH}$ as shown in Figures 3(a), 3(b), and 3(c). The contact time between the adsorbent and adsorbate was 20 minutes for all experiments. As these figures indicate, the efficiency of arsenate removal increases with increasing in the concentration of GT-NZVI.

The increase in the efficiency of arsenate removal with increasing in the concentration of GT-NZVI is in accord with the results of other researcher [15, 21]. It can be attributed to the increase in surface area of adsorbent at higher dosages that increased the sites for arsenate adsorption. Increase in the active surface sites increases the possibility of collision between nanoparticles and arsenate ions [22]. Also, more available surface area is provided for oxidation and deduction reactions [23].

3.3. Effect of $p H$ on $A s(V)$ Removal. The $\mathrm{pH}$ effect on $\mathrm{As}(\mathrm{V})$ removal by GT-NZVI was studied and the results are indicated in Figures 4(a), 4(b), and 4(c). During the examination, the amount of adsorbent $(0.1,0.55$, and $1 \mathrm{~g} / \mathrm{L})$ and ultrasonic power $(0,150$, and $300 \mathrm{~W})$ were kept constant. Increase in
$\mathrm{pH}$ from 3 to approximately 5.5-7 leads to increase in the efficiency of removal; however, increasing the $\mathrm{pH}$ further decreases the removal efficiency. In other words, at highly acidic or highly alkaline conditions, the efficiency of NZVI toward arsenate adsorption was depleted.

Results of other studies confirm this finding [10, 24]. The removal mechanism of arsenic ions by NZVI in aqueous medium is primarily a result of adsorption and coprecipitation of arsenic ions with oxides of iron(II) and iron(III) and ferric hydroxide that developed during NZVI oxidation [10]. In the $\mathrm{pH}$ range of 5.5 to 7 , the amorphous hydroxide solid of ferric ion is stable; therefore, the arsenate adsorption on NZVI is excessive. On the contrary, outside this range the efficiency decreased because of instability of iron hydroxide [24]. At high $\mathrm{pH}, \mathrm{H}_{2} \mathrm{AsO}^{3-}$ is the predominant form of arsenic species, while the NZVI corrosion product surfaces are also negative $\left(\mathrm{Fe}(\mathrm{III})-\mathrm{O}^{-}\right)$causing electrostatic repulsion [10].

3.4. Effects of Ultrasonic Wave Power on As(V) Removal. The effect of ultrasonic power on $\mathrm{As}(\mathrm{V})$ removal at constant adsorbent amount $(0.1,0.55$, and $1 \mathrm{~g} / \mathrm{L})$ and constant $\mathrm{pH}$ $(3,7$, and 11) is shown in Figures 5(a), 5(b), and 5(c). The positive effect is more pronounce at 0.1 and $0.55 \mathrm{~g} / \mathrm{L}$ adsorbent dosages and $\mathrm{pH} 3$ (acidic solution) in which the $\mathrm{As}(\mathrm{V})$ removal efficiency improves with increasing ultrasonic power. On the other hand, at $\mathrm{pH} 11$ (alkali solution) the $\mathrm{As}(\mathrm{V})$ 


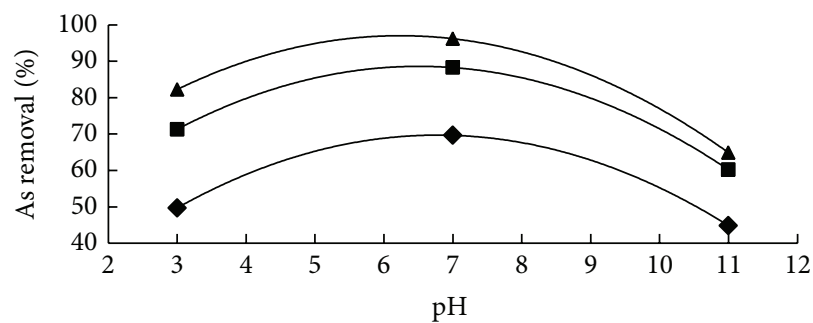

- $0.1 \mathrm{~g} / \mathrm{L}$ NZVI

- $0.55 \mathrm{~g} / \mathrm{L}$ NZVI

- $1 \mathrm{~g} / \mathrm{L}$ NZVI

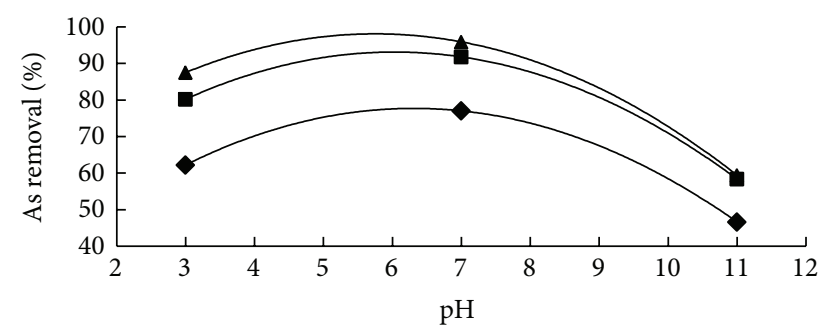

- $0.1 \mathrm{~g} / \mathrm{L}$ NZVI

- $0.55 \mathrm{~g} / \mathrm{L}$ NZVI

- $1 \mathrm{~g} / \mathrm{L}$ NZVI

(a) Ultrasonic power $=0 \mathrm{~W}$

(b) Ultrasonic power $=150 \mathrm{~W}$

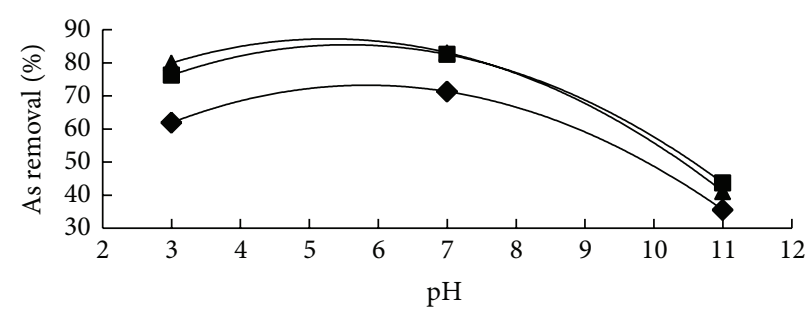

- $0.1 \mathrm{~g} / \mathrm{L}$ NZVI

- $0.55 \mathrm{~g} / \mathrm{L}$ NZVI

- $1 \mathrm{~g} / \mathrm{L}$ NZVI

(c) Ultrasonic power $=300 \mathrm{~W}$

FIGURE 4: $\mathrm{As}(\mathrm{V})$ removal efficiency versus $\mathrm{pH}$ at different ultrasonic powers.
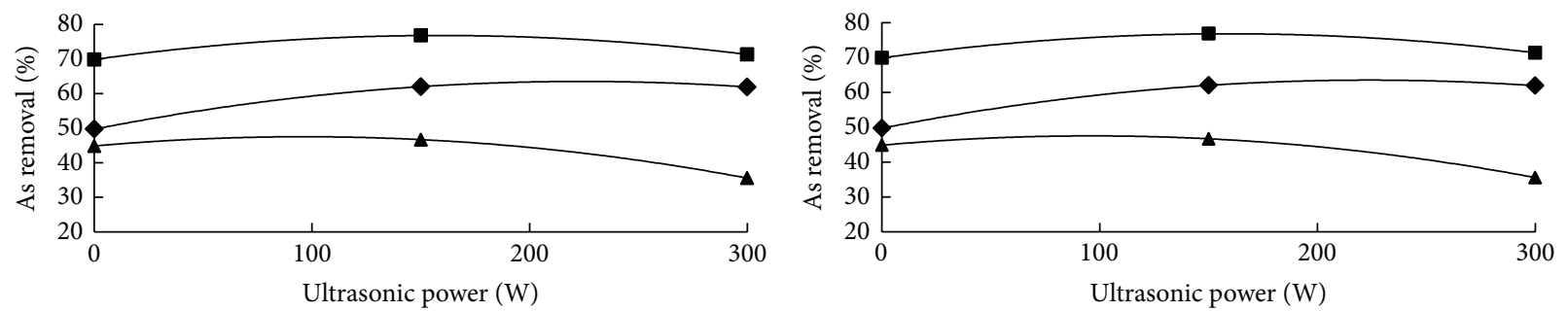

- $\mathrm{pH}=3$

- $\mathrm{pH}=7$

- $\mathrm{pH}=3$

- $\mathrm{pH}=7$

\ $\mathrm{pH}=11$

A $\mathrm{pH}=11$

(a) $0.1 \mathrm{~g} / \mathrm{L} \mathrm{NZVI}$

(b) $0.55 \mathrm{~g} / \mathrm{L} \mathrm{NZVI}$

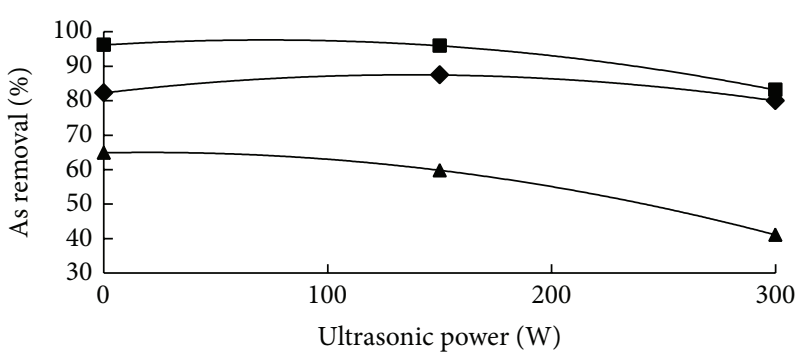

$\bullet \mathrm{pH}=3$

- $\mathrm{pH}=7$

- $\mathrm{pH}=11$

(c) $1 \mathrm{~g} / \mathrm{L}$ NZVI

Figure 5: As(V) Removal efficiency versus ultrasonic wave power. 


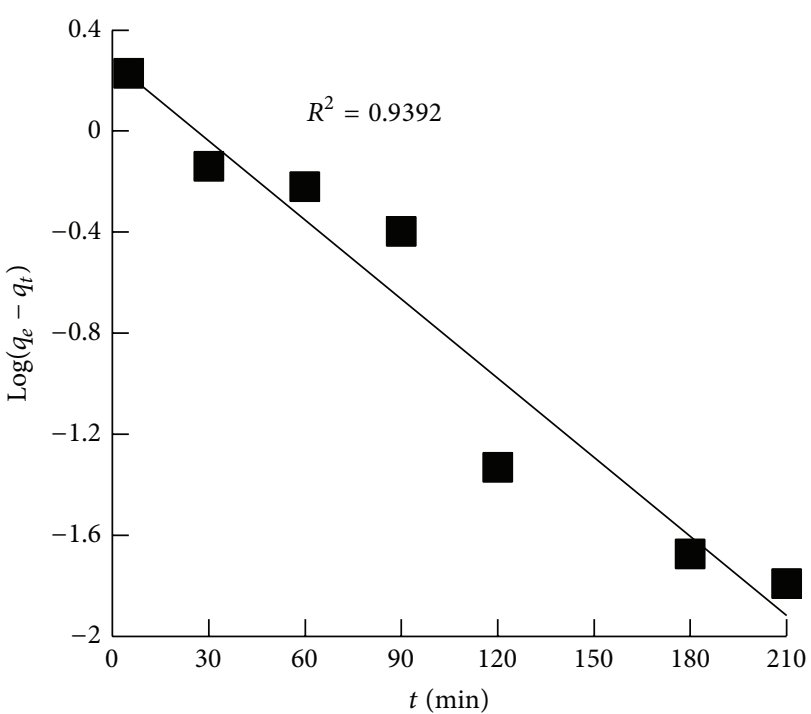

(a)

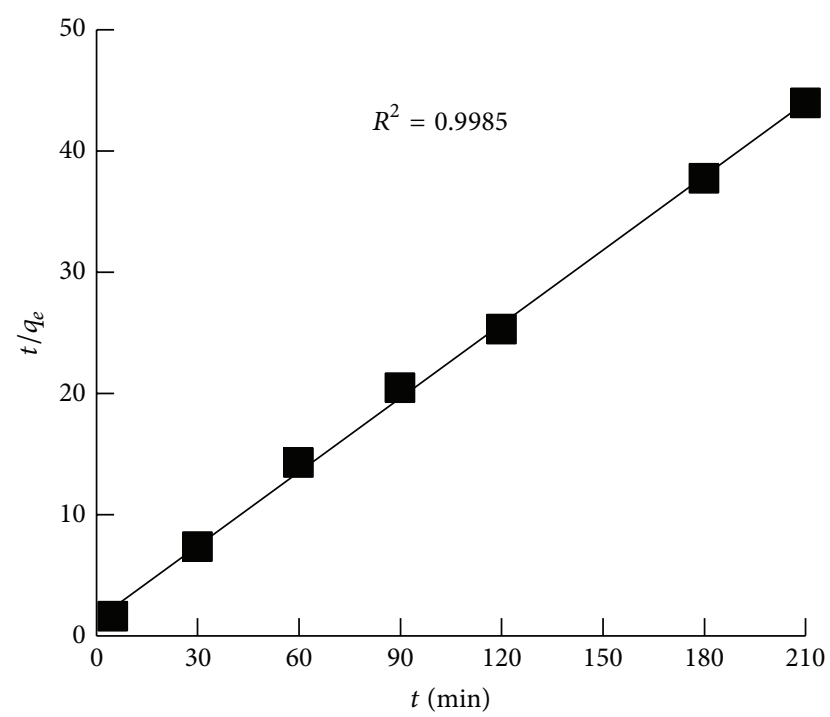

(b)

Figure 6: (a) Pseudo-first-order and (b) pseudo-second-order kinetics models.

TABLE 1: Calculated parameters in Langmuir and Freundlich models.

\begin{tabular}{lccc}
\hline & $K_{L}\left(\mathrm{~L} \mathrm{mg}^{-1}\right)$ & $q_{m}\left(\mathrm{mg} \mathrm{g}^{-1}\right)$ & $R^{2}$ \\
\hline Langmuir parameters & 0.663 & 34.2 & 0.9963 \\
\hline Freundlich parameters & $K_{F}$ & $n$ & $R^{2}$ \\
\hline
\end{tabular}

removal efficiency reduces with increasing ultrasonic power. In neutral aqueous solutions ( $\mathrm{pH} 7$ ) and adsorbent dosages of 0.1 and $0.55 \mathrm{~g} / \mathrm{L}$, the $\mathrm{As}(\mathrm{V})$ removal efficiency increases with increasing ultrasonic power to a maximum at ultrasonic power of $150 \mathrm{~W}$ and then decreases afterward as the ultrasonic power increase from $150 \mathrm{~W}$ to $300 \mathrm{~W}$.

Improvement of $\mathrm{As}(\mathrm{V})$ removal efficiency with increasing ultrasonic power is probably due to more dispersion of GTNZVI particles in acidic solution at low dosage of NZVI (0.1 and $0.55 \mathrm{~g} / \mathrm{L}$ ). However, at the higher NZVI concentration $(1 \mathrm{~g} / \mathrm{L})$ more collisions lead to increase in agglomeration rate that result in $\mathrm{As}(\mathrm{V})$ removal efficiency reduction.

In higher $\mathrm{pH}$ (alkali conditions), the dissolved ferrous ions collided with hydroxyl ions to give ferrous hydroxide precipitation on the iron outer surface. The sedimentation fills the outside active sites of nanoparticles and prevents it from adsorbing arsenate [15]. On the other hand, ultrasonication is associated with cavitation that produces very reactive hydroxyl radicals [25]. The produced $\mathrm{OH}^{*}$ radicals also that are deposited on active sites of nanoparticles lead to decrease in the removal efficiency of arsenate from water. Also as explained in the previous section, at high $\mathrm{pH}, \mathrm{H}_{2} \mathrm{AsO}^{3-}$ is the principal form of arsenic species, while the NZVI corrosion product surfaces are also negative $\left(\mathrm{Fe}(\mathrm{III})-\mathrm{O}^{-}\right.$) producing electrostatic repulsion [10]. This explanation may justify the decreases in $\mathrm{As}(\mathrm{V})$ removal efficiency with increasing the ultrasonic wave power at high $\mathrm{pH}$ solutions.
3.5. As $(V)$ Adsorption Kinetics. There are a number of kinetic models to identify the performance of the adsorbent and to inspect the dominating mechanism of the adsorption process [26-29]. To study the mechanism of adsorption process the experimental kinetic data for the uptake of $\mathrm{As}(\mathrm{V})$ by NZVI particles were modeled using the following equations of pseudo-first-order (1) and pseudo-second-order (2):

$$
\begin{gathered}
q_{t}=q_{e}\left[1-e^{-K_{1} t}\right], \\
q_{t}=\frac{t K_{2} q_{e}^{2}}{1+t K_{2} q_{e}} .
\end{gathered}
$$

Linearization of the above equation gives (3) and (4), respectively, as follows:

$$
\begin{gathered}
\log \left(q_{e}-q_{t}\right)=\log \left(q_{e}\right)-\frac{K_{1}}{2.303} t, \\
\frac{t}{q_{t}}=\frac{1}{K_{2} q_{e}^{2}}+\frac{1}{q_{e}} t .
\end{gathered}
$$

In above equations, $q_{t}$ is the amount of $\mathrm{As}(\mathrm{V})$ adsorbed per unit of adsorbent $\left(\mathrm{mg} \mathrm{g}^{-1}\right)$ at time $t, K_{1}$ the pseudo-firstorder rate constant $\left(\mathrm{min}^{-1}\right), t$ the contact time $(\mathrm{min}), K_{2}$ the pseudo-second-order rate constant $\left(\mathrm{g} \mathrm{mg}^{-1} \mathrm{~min}^{-1}\right)$, and $q_{e}$ equilibrium adsorption capacity $\left(\mathrm{mg} \mathrm{g}^{-1}\right)$.

Figure 6 illustrates plots of linearized form of pseudofirst-order and pseudo-second-order equations for the experimental data. The value of regression coefficient $\left(R^{2}\right)$ for pseudo-first-order model is less than that for pseudo-secondorder as indicated in Figure 6. Therefore, the pseudo-secondorder kinetic model matches better the experimental data than the pseudo-first-order model does and the studied sorption of $\mathrm{As}(\mathrm{V})$ by GT-NZVI follows a pseudo-secondorder model. The results are in agreement with the literature [30]. 


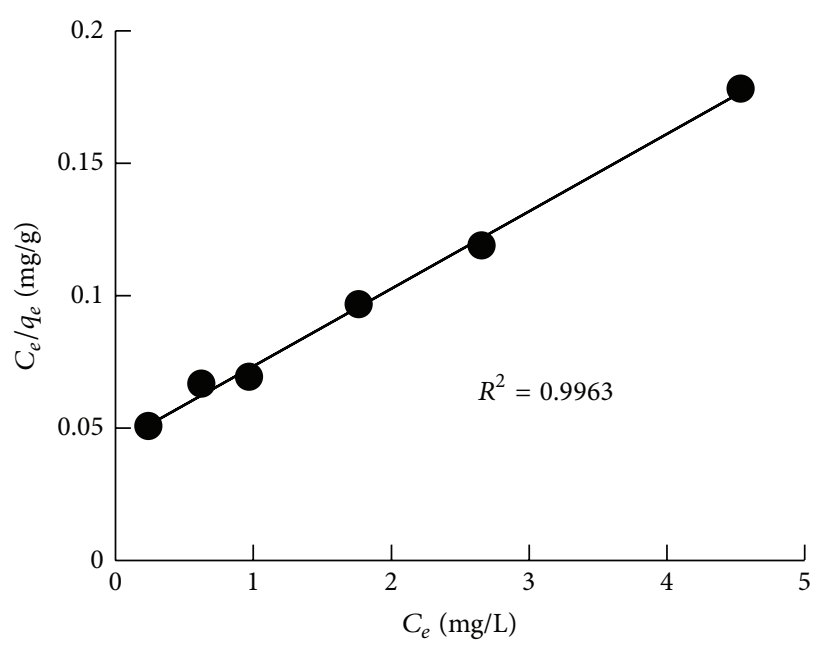

(a)

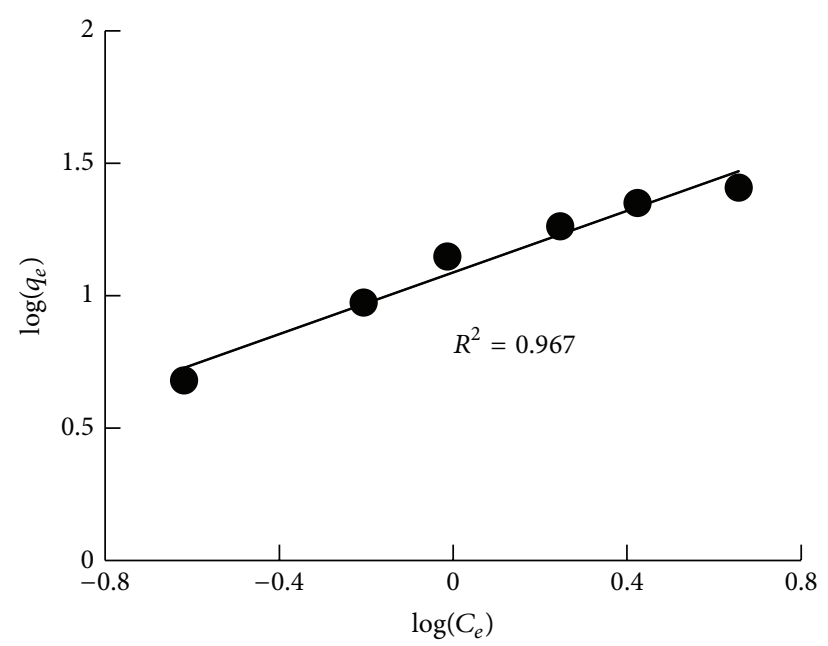

(b)

Figure 7: (a) Langmuir and (b) Freundlich isotherms.

TABLE 2: Comparison of experimental adsorption capacity with the literature.

\begin{tabular}{|c|c|c|c|c|}
\hline Adsorbent & $q_{m}(\mathrm{mg} / \mathrm{g})$ & $C_{e}$ range $(\mathrm{mg} / \mathrm{L})$ & Model & References \\
\hline LECA modified with Fenton & 0.058 & $0.1-0.3$ & Langmuir & {$[5]$} \\
\hline Hardened paste of Portland cement & 3.98 & 0.2 & Freundlich & {$[33]$} \\
\hline Pine leaves & 3.27 & $5-30$ & Langmuir & [34] \\
\hline $\mathrm{CuO}$ nanoparticle & 26.9 & $0.1-100$ & Langmuir & {$[35]$} \\
\hline Magnetic wheat straw & 8.06 & $1-28$ & Langmuir & {$[36]$} \\
\hline Supported NZVI on activated carbon & 12.02 & 2 & Langmuir & {$[21]$} \\
\hline Nano- $\mathrm{TiO}_{2}$ & 37.5 & 1 & Freundlich & {$[37]$} \\
\hline GT-NZVI & 34.2 & $5-30$ & Langmuir & This study \\
\hline
\end{tabular}

3.6. Adsorption Isotherms. The adsorption isotherm points out how the adsorbate is distributed between the liquid phase and the solid adsorbent when an equilibrium state was accomplished at constant temperature. The two familiar equilibrium models of Freundlich [31] and Langmuir [32] were used in the analysis of experimental data. In Langmuir model (5), a monolayer adsorption on homogeneous surface is presumed; however, the Freundlich model (6) is empirical and it can be used for multilayer adsorption on a heterogeneous surface. The linearized forms of the equations are provided as follows:

$$
\begin{gathered}
\frac{C_{e}}{q_{e}}=\frac{1}{q_{m} K_{L}}+\frac{C_{e}}{q_{m}}, \\
\log q_{e}=\log K_{F}+\frac{1}{n} \log C_{e} .
\end{gathered}
$$

Figure 7 shows the adsorption isotherms of arsenate adsorption at $\mathrm{pH} 6$ and room temperature. The capability of the two isotherm models is evaluated by calculating the correlation coefficients $R^{2}$, and the results are illustrated in Table 1. The correlation coefficient of Langmuir model (0.9963) is more than that of Freundlich model (0.9670) which reveals the more suitability of Langmuir model to fit the experimental equilibrium data.
The reported adsorption capacity of NZVI in the literature is shown in Table 2. The synthesized NZVI has a capacity of $34.2 \mathrm{mg} / \mathrm{g}$ toward arsenate, which is higher than the adsorption capacity of many of reported adsorbents in Table 2 .

\section{Conclusions}

GT-NZVI adsorbent was synthesized using aqueous solution of $\mathrm{FeSO}_{4} \cdot 7 \mathrm{H}_{2} \mathrm{O}$ and green tea extract as a reducing agent. Analysis of FESEM and XRD images indicated that the GT-NZVI particles had spherical shapes collected in texture structure with diameter sizes approximately $30 \mathrm{~nm}$. Batch adsorption investigation showed that the synthesized adsorbent was successful for the elimination of arsenate with comparatively rapid kinetics. The adsorbent revealed high elimination efficiency of arsenate from water at approximately $\mathrm{pH}$ 6. The $\mathrm{As}(\mathrm{V})$ adsorption capacity at $\mathrm{pH} 6$ was $34.2 \mathrm{mg} / \mathrm{g}$, which is greater than many of reported data on arsenic capacity in the literature. At small adsorbent dosages and acidic solution the As(V) removal efficiency improved with increasing ultrasonic power. However, in strong alkali solutions, arsenic removal efficiency decreased with increasing ultrasonic wave power. 


\section{Conflict of Interests}

The authors declare that they have no conflict of interests regarding the publication of this paper.

\section{Acknowledgment}

Abadan Faculty of Petroleum Engineering at Petroleum University of Technology has supported this research.

\section{References}

[1] P. C. Nagajyoti, K. D. Lee, and T. V. M. Sreekanth, "Heavy metals, occurrence and toxicity for plants: a review," Environmental Chemistry Letters, vol. 8, no. 3, pp. 199-216, 2010.

[2] M. E. Sears, "Chelation: harnessing and enhancing heavy metal detoxification-a review," The Scientific World Journal, vol. 2013, Article ID 219840, 13 pages, 2013.

[3] F. Abu Bakar, I. Yusoff, N. T. Fatt, F. Othman, and M. A. Ashraf, "Arsenic, zinc, and aluminium removal from gold mine wastewater effluents and accumulation by submerged aquatic plants (Cabomba piauhyensis, Egeria densa, and Hydrilla verticillata)," BioMed Research International, vol. 2013, Article ID 890803, 7 pages, 2013.

[4] M. A. Bavio and A. G. Lista, "Synthesis and characterization of hybrid-magnetic nanoparticles and their application for removal of arsenic from groundwater," The Scientific World Journal, vol. 2013, Article ID 387458, 7 pages, 2013.

[5] F. Kord Mostafapour, E. Bazrafshan, M. Farzadkia, and S. Amini, "Arsenic removal from aqueous solutions by Salvadora persica stem ash," Journal of Chemistry, vol. 2013, Article ID 740847, 8 pages, 2013.

[6] M. I. Danish, I. A. Qazi, A. Zeb, A. Habib, M. A. Awan, and Z. Khan, "Arsenic removal from aqueous solution using pure and metal-doped titania nanoparticles coated on glass beads: adsorption and column studies," Journal of Nanomaterials, vol. 2013, Article ID 873694, 17 pages, 2013.

[7] N. Mirza, Q. Mahmood, M. M. Shah, A. Pervez, and S. Sultan, "Plants as useful vectors to reduce environmental toxic arsenic content," The Scientific World Journal, vol. 2014, Article ID 921581, 11 pages, 2014.

[8] J. A. G. Gomes, P. Daida, M. Kesmez et al., "Arsenic removal by electrocoagulation using combined Al-Fe electrode system and characterization of products," Journal of Hazardous Materials, vol. 139, no. 2, pp. 220-231, 2007.

[9] S. R. Kanel, J.-M. Greneche, and H. Choi, "Arsenic(V) removal from groundwater using nano scale zero-valent iron as a colloidal reactive barrier material," Environmental Science and Technology, vol. 40, no. 6, pp. 2045-2050, 2006.

[10] S. R. Kanel, B. Manning, L. Charlet, and H. Choi, "Removal of arsenic(III) from groundwater by nanoscale zero-valent iron," Environmental Science and Technology, vol. 39, no. 5, pp. 12911298, 2005.

[11] H. Amiri, N. Jaafarzadeh, M. Ahmadi, and S. S. Martínez, "Application of LECA modified with Fenton in arsenite and arsenate removal as an adsorbent," Desalination, vol. 272, no. 1-3, pp. 212-217, 2011.

[12] D. L. Guerra, A. C. Batista, P. C. Corrêa da costa, R. R. Viana, and C. Airoldi, "Adsorption of arsenic ions on Brazilian sepiolite: effect of contact time, $\mathrm{pH}$, concentration, and calorimetric investigation," Journal of Colloid and Interface Science, vol. 346, no. 1, pp. 178-187, 2010.
[13] S. M. Seyedi, B. Anvaripour, M. Motavassel, and N. Jadidi, "Comparative cadmium adsorption from water by nanochitosan and chitosan," International Journal of Engineering and Innovative Technology, vol. 2, no. 9, pp. 145-148, 2013.

[14] M. Khalil, K. Z. Al-Wakeel, S. S. Abd El Rehim, and H. Abd El Monem, "Removal of arsenate from aqueous media by magnetic chitosan resin immobilized with molybdate oxoanions," International Journal of Environmental Science and Technology, vol. 11, pp. 1051-1062, 2014.

[15] R. Rahmani, H. R. Ghaffari, and M. T. Samadi, "A Comparative study on arsenic (III) removal from aqueous solution using nano and micro sized zero valent iron," Iranian Journal of Environmental Health Science \& Engineering, vol. 8, no. 2, pp. 175-180, 2011.

[16] T. Shahwan, S. Abu Sirriah, M. Nairat et al., "Green synthesis of iron nanoparticles and their application as a Fenton-like catalyst for the degradation of aqueous cationic and anionic dyes," Chemical Engineering Journal, vol. 172, no. 1, pp. 258-266, 2011.

[17] S. Machado, W. Stawiński, P. Slonina et al., "Application of green zero-valent iron nanoparticles to the remediation of soils contaminated with ibuprofen," Science of the Total Environment, pp. 461323-464629, 2013.

[18] G. E. Hoag, J. B. Collins, J. L. Holcomb, J. R. Hoag, M. N. Nadagouda, and R. S. Varma, "Degradation of bromothymol blue by "greener" nano-scale zero-valent iron synthesized using tea polyphenols," Journal of Materials Chemistry, vol. 19, no. 45, pp. 8671-8677, 2009.

[19] M. N. Nadagouda, A. B. Castle, R. C. Murdock, S. M. Hussain, and R. S. Varma, "In vitro biocompatibility of nanoscale zerovalent iron particles (NZVI) synthesized using tea polyphenols," Green Chemistry, vol. 12, no. 1, pp. 114-122, 2010.

[20] M. Bettinelli, U. Baroni, and N. Pastorelli, "Determination of arsenic, cadmium, lead, antimony, selenium and thallium in coal fly ash using the stabilised temperature platform furnace and Zeeman-effect background correction," Journal of Analytical Atomic Spectrometry, vol. 3, no. 7, pp. 1005-1001, 1988.

[21] H. Zhu, Y. Jia, X. Wu, and H. Wang, "Removal of arsenic from water by supported nano zero-valent iron on activated carbon," Journal of Hazardous Materials, vol. 172, no. 2-3, pp. 1591-1596, 2009.

[22] H. Koohpayehzadeh Esfahaani, A. Torabian, G. Nabibidhendi, and T. Yazdanparast, "Nanoparticle zerovalent iron effects on Arsenic(V) removal," in Proceedings of the 4th International Conference on Nanostructures, pp. 12-14, Kish Island, Iran, 2011.

[23] M. Chrysochoou, M. McGuire, and G. Dahal, "Transport characteristics of green-tea nano-scale zero valent iron as a function of soil mineralogy," Chemical Engineering Transactions, vol. 28, pp. 121-126, 2012.

[24] M. Donmez and F. Akbal, "The removal of As(V) from drinking waters by coagulation process using Iron salts," World Academy of Science, Engineering and Technology, vol. 78, pp. 437-439, 2011.

[25] C. Gong and D. P. Hart, "Ultrasound induced cavitation and sonochemical yields," Journal of the Acoustical Society of America, vol. 104, no. 5, pp. 2675-2682, 1998.

[26] I. Küncek and S. Şener, "Adsorption of methylene blue onto sonicated sepiolite from aqueous solutions," Ultrasonics Sonochemistry, vol. 17, no. 1, pp. 250-257, 2010.

[27] Y.-S. Ho, "Citation review of Lagergren kinetic rate equation on adsorption reactions," Scientometrics, vol. 59, no. 1, pp. 171-177, 2004. 
[28] Y. S. Ho and G. McKay, "Sorption of dye from aqueous solution by peat," Chemical Engineering Journal, vol. 70, no. 2, pp. 115124, 1998.

[29] Y.-S. Ho, "Review of second-order models for adsorption systems," Journal of Hazardous Materials, vol. 136, no. 3, pp. 681689, 2006.

[30] Y. S. Ho and G. McKay, "Pseudo-second order model for sorption processes," Process Biochemistry, vol. 34, no. 5, pp. 451$465,1999$.

[31] H. M. F. Freundlich, "Über die adsorption in lösungen," Zeitschrift für Physikalische Chemie, vol. 57, pp. 385-470, 1906.

[32] I. Langmuir, "The constitution and fundamental properties of solids and liquids. Part I. Solids," The Journal of the American Chemical Society, vol. 38, no. 2, pp. 2221-2295, 1916.

[33] S. Kundu, S. S. Kavalakatt, A. Pal, S. K. Ghosh, M. Mandal, and T. Pal, "Removal of arsenic using hardened paste of Portland cement: batch adsorption and column study," Water Research, vol. 38, no. 17, pp. 3780-3790, 2004.

[34] U. Shafique, A. Ijaz, M. Salman et al., "Removal of arsenic from water using pine leaves," Journal of the Taiwan Institute of Chemical Engineers, vol. 43, no. 2, pp. 256-263, 2012.

[35] C. A. Martinson and K. J. Reddy, "Adsorption of arsenic(III) and arsenic (V) by cupric oxide nanoparticles," Journal of Colloid and Interface Science, vol. 336, no. 2, pp. 406-411, 2009.

[36] Y. Tian, M. Wu, X. Lin, P. Huang, and Y. Huang, "Synthesis of magnetic wheat straw for arsenic adsorption," Journal of Hazardous Materials, vol. 193, pp. 10-16, 2011.

[37] M. E. Pena, G. P. Korfiatis, M. Patel, L. Lippincott, and X. Meng, "Adsorption of $\mathrm{As}(\mathrm{V})$ and $\mathrm{As}(\mathrm{III})$ by nanocrystalline titanium dioxide," Water Research, vol. 39, no. 11, pp. 2327-2337, 2005. 

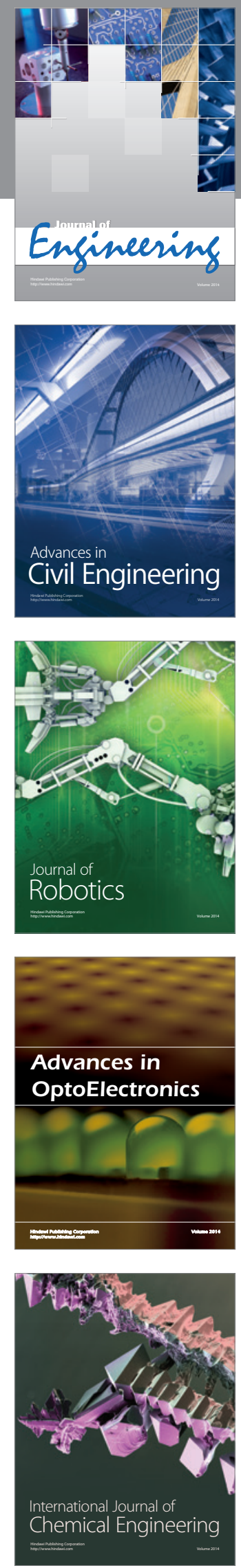

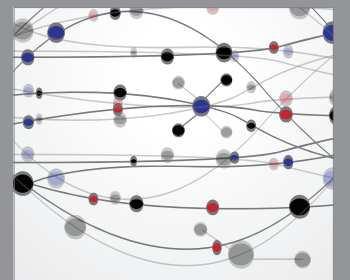

The Scientific World Journal
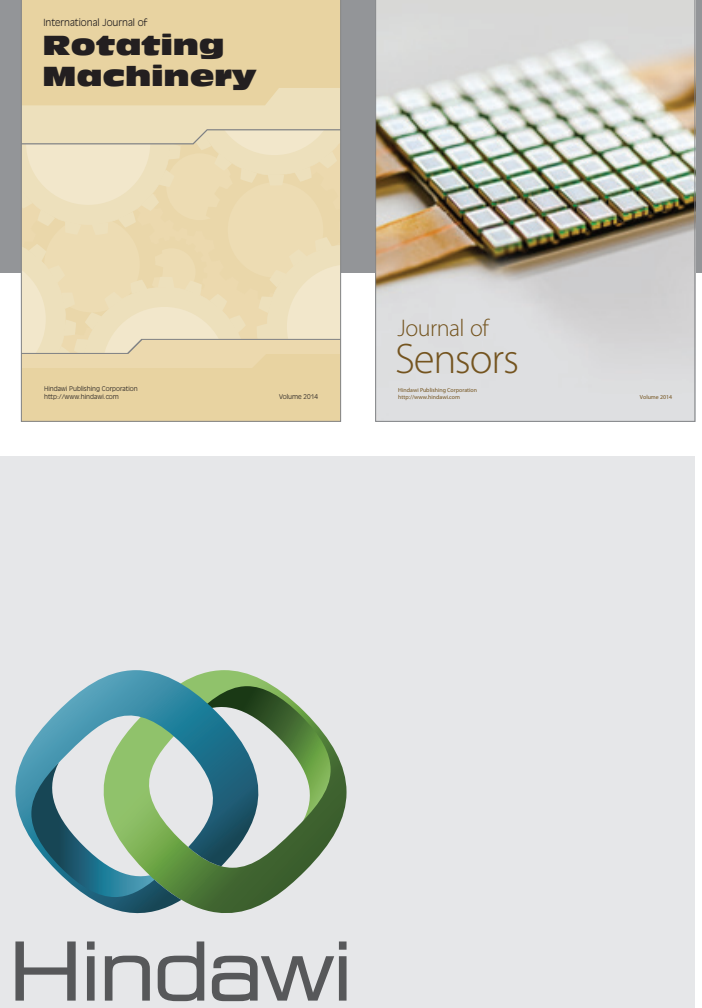

Submit your manuscripts at http://www.hindawi.com
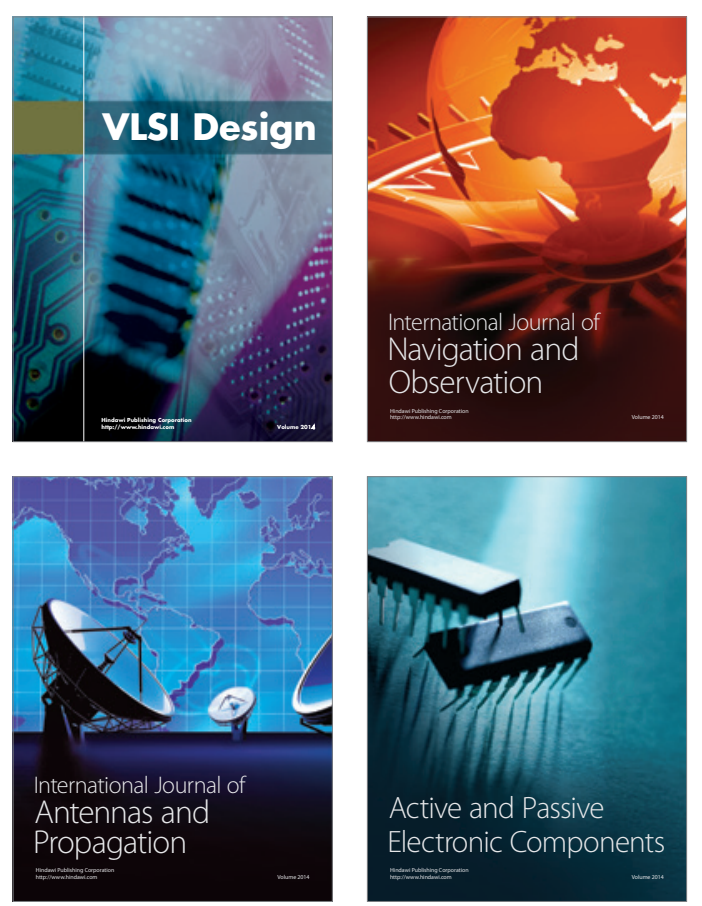
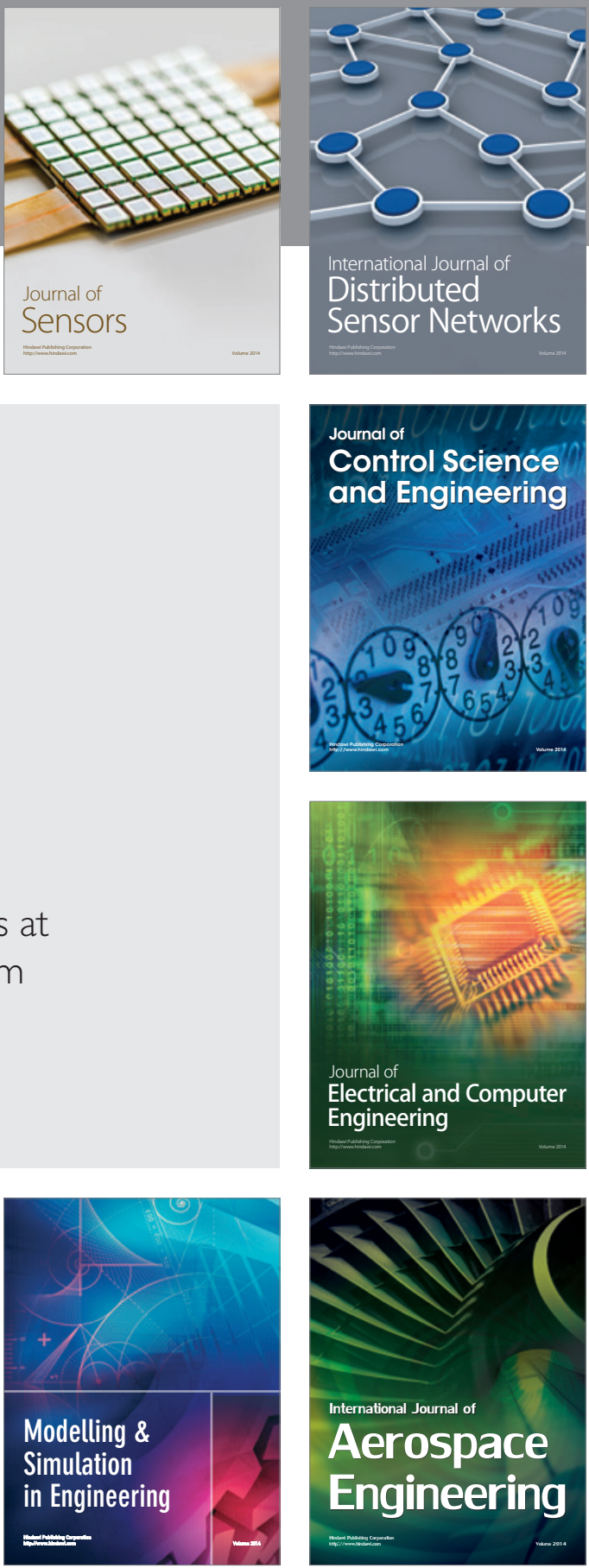

Journal of

Control Science

and Engineering
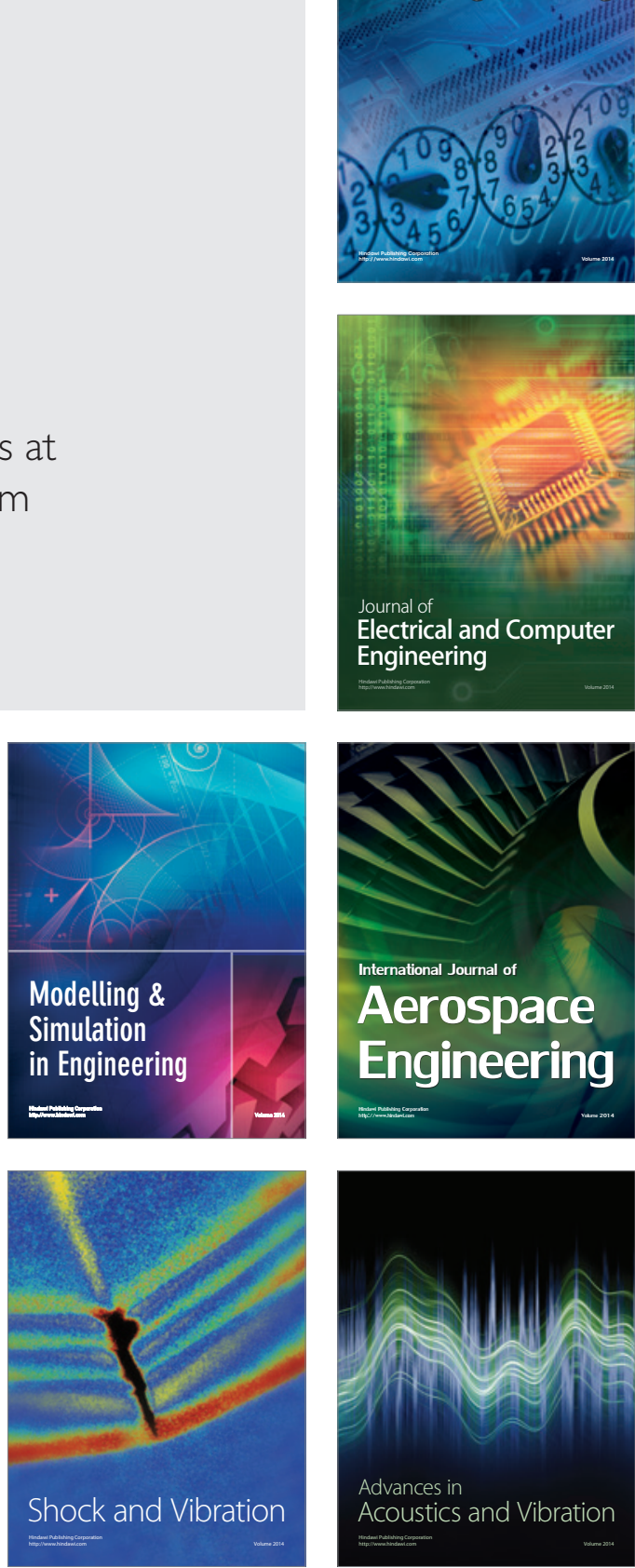